\title{
I wear Prada, because I want to.
}

\author{
Nastaran Norouzi Richards-Carpenter \\ Assistant Professor in Marketing and Fashion Management, \\ Richmond the International American University in London
}

\begin{abstract}
:
Previous studies on luxury consumption indicated that women may use luxury consumption as a self-promotion strategy during within-sex competitions, as these luxuries improve their advantages against same sex rivals for mates. Many of these studies rely on costly signalling and intra-sexual competition theory, and they suggest female intra-sexual competition in a mate attraction context triggers women's spending on luxury products. The focus of this paper is to understand the gender-related motivations, specifically for female consumers in the luxury market and to compare and contrast the new findings with the previous studies. The finding of this study demonstrates other motives in female luxury consumer behaviour rather than relationship, self-enhancement and competition.
\end{abstract}

Keywords: women, empowerment, motives, culture, luxury consumption, gender trait change

\section{Introduction:}

Over the past three decades, the luxury-brand industry has experienced unprecedented growth: the global market for personal luxury brands was estimated at $€ 224$ billion in 2015, delivering a healthy growth of $5 \%$ year on year (Bain and Company 2015). Female luxury consumers account for a big chunk of the luxury market, as they are willing to spend large sums of money on conspicuous luxuries, such as Louboutin shoes, Louis Vuitton purses, or Armani dresses (Chao and Schor, 1998; Stokburger-Sauer and Teichmann, 2011). American women acquire on average three new handbags each year (Bev et al, 2011), prominently flaunting designer brands such as Fendi, Gucci, Louis Vuitton, Marc Jacobs, Christian Dior, Prada, and Chanel (Nunes et al, 2010). In the United States alone, spending on luxury goods amounts to as much as $\$ 525$ billion per year (Bev and Zolenski 2011), with women's products accounting for over half of this consumption (D’Arpizio 2011). Given women's passion for pricey possessions, why do women desire luxury goods?

Previous studies show male and female luxury consumers demonstrate different motivations for purchasing luxury products and, therefore, may differ in terms of their value perceptions toward luxury brands (Tynan, McKechnie, and Chhuon 2010). Several researches have shown that men ostentatiously spend their money on luxury brands to signal their mate value to women; however, research on the motivations for female luxury consumption is rather scarce (Hudders, 2012; Wang and Griskevicius, 2014).

Hudders et al (2014) in their article, The Rival Wears Prada, investigated the Luxury Consumption as a Female Competition Strategy and concluded some interesting results which shows females have different attitudes and purposes toward the personal self-enhancing luxury products and the non-self-enhancing products. There are a number of studies which investigate female consumer buying behaviour in luxury shopping through an understanding of romantic relationships, as it's believed that luxury goods are known to serve an important function in relationships for men and, accordingly, that such goals may help to attract romantic partners (Griskevicius et al. 2007). This study's focus is to investigate what additional or alternative motives to romantic relationship, mate-guarding and signalling function may exist for female luxury shoppers when they spending their money on luxury products.

\section{Theories}

To understand the female motivations in buying luxury goods, various studies and researches have been conducted and some studies have relied on costly signalling and intra-sexual competition theory (Griskevicius et al., 2007; Miller, 2009; Nelissen and Meijers, 2011; Saad, 2007, 2011; Saad and Vongas, 2009; Sundie et al., 2011) to explain the females' motives 
in luxury shopping by suggesting that female intra-sexual competition in a mate attraction context triggers women's spending on luxuries. Intrasexual competition occurs when individuals compete to gain access to limited resources that they do not want to share (Cox and Fisher, 2008). This involves same-sex competition for access to potential and desirable mates (Rosvall, 2011) and competition to retain a mate (Schmitt and Buss, 1996). Wang and Griskevicius (2014) found that women use luxury consumption as a mate retention strategy. More specifically, their studies indicate that women display luxuries to deter same sex others who are perceived as a threat towards a romantic relationship.

In addition to male retention strategy, signalling theory in this context indicates that women's luxury products function as a signalling system directed at other women who pose threats to their romantic relationships. Additional studies revealed that women use pricey possessions to signal that their romantic partner is especially devoted to them. (Griskevicius et al. 2007)

Men and women differ in the characteristics they pay attention to when selecting potential mates (Buss, 1999; Miller, 2000). Women tend to look for reliable men with high social status and good financial prospects, such that they mate with men who are both able and willing to invest their time and resources into a relationship (Buss, 1999).

These preferences are adaptive because they enable women to select a mate who will help them ensure the survival of their children, thereby increasing their inclusive fitness. Men, on the other hand, highly value youthfulness and physical attractiveness in women. These preferences evolved because these observable features signal fertility and reproductive potential, which are characteristics that can maximize the reproductive success of men via increased numbers of healthy children (Buss, 1999).

The bedrock of the findings above, is what is called 'gender role' which is a set of societal norms dictating the types of behaviours which are generally considered acceptable, appropriate, or desirable for people based on their actual or perceived sex or sexuality. The extension of the concept of gender roles on consumer behaviour results in conceptions of femininity and masculinity in purchasing products.

Research on gender differences in consumption generally states that the different life orientations of men and women influence their consumer behaviour. While men strongly follow agentic goals, that are, life goals directed toward taskoriented thinking and performance-motivated acting, women more strongly follow communal goals, that are, life goals directed toward social and emotional relationships with others (Meyers-Levy, 1988; Prakash, 1992). Research, however, has also recognized the fact that gender roles are becoming increasingly blurred. The changes in gender roles and the possible impact of that on consumer buying behaviour of luxury products is one of the main focuses of this research to investigate whether female luxury shoppers buy luxury products to compete with other females and to retain their partners or whether there are other underlying factors those have been ignored in many of the previous studies.

Many of such previous studies have the following in common: 1)They are mostly quantitative, 2)They are conducted in developed countries, 3)Females' age and cultural differences haven't been taken into account and 4)the dynamics and changes in sex-typing such as possessing more male traits haven't been fully investigated across the researches.

\section{Methodology:}

The need for a more comprehensive study across the various cultures and female age range to uncover more variables in females' motive in spending money on luxury products led this study toward a more in-depth study through a semi structured interview and qualitative study in four phases:

Phase one: Qualitative research in London luxury market

Phases two: Qualitative research in Tehran, Iran

Phase three: Qualitative research in Kuala Lumpur, Malaysia

Phase four: Comparisons, analysis and conclusion

The focus of this paper is to identify what are the motivations behind female luxury shopping in addition to what was suggested in previous studies and whether the result of this study confirms the previous findings or not therefore, in order to answer the main question of this paper, qualitative research design was chosen to gain an understanding of underlying reasons, opinions, and motivations. It provides insights into the problem or helps to develop ideas or hypotheses for potential quantitative research. 
The data collection of phase one of this study was completed between May and August 2017. For an in-depth understanding of the intention female luxury shoppers, a qualitative research design has been selected. A semi structured interview which enabled females to answer the questions and express themselves freely was designed. There were around 20 questions asked in each interview in London and each interview took between 35 to 75 minutes. The sample was mostly selected through referral and personal contacts in London Fashion Shows, opening and launch of new luxury brands and shops. Females who took part in the interviews were between ages 20 to 52 and that was because no female above age 52 consented to be interviewed. In addition to interviewing 24 female luxury shoppers, a colleague put me in contact with an experiences personal shopper in Harrods which was very helpful in understanding the underlying motives of female in buying luxury products. All respondents were informed about the general aims of the study, their anonymity was guaranteed and all gave full consent. All interviews were recorded and transcribed mostly by myself and the manual coding system was used for data analysis purpose.

The interviews mainly focused on the purchases of personal fashion luxury products such as luxury sunglasses, handbags, jewelleries and outfits rather than other luxury items such as cars, collectable items and mobile phones.

\section{Result:}

Brand image and following friends and celebrity trends were the most important variables mentioned by female shoppers across any ages. Respondent 5 (R5) who was 45 years mentioned:

"The reason I buy a piece of jewellery or a new luxury handbag is when I see someone that I know has a beautiful jewellery or handbag, I feel curious and I investigate the brand or the collection and I buy a similar or even nicer item [...] my friends are the source of information and motivation for me".

R5 she has no feeling of competition to anyone and sometimes she doesn't even tell her husband about her shopping and she mostly wear her new luxury goods when she goes out with her female friends or on her own as she feels better about herself and she feels she looks nicer.

R11, who buys at least one luxury fashion items every two weeks said:

"If I see a middle age lady wearing so many luxury items I think that lady is a successful career woman, I don't think her husband necessarily bought them for her [...] but if I see any female is wearing a lot of luxury items with a lot of logos on them and the lady has a lot of make up on her face, I feel a bit sad for her and I think she is lonely and looking for a partner rather than she is trying to secure her current relationship".

Sixteen of respondents mentioned they buy luxury fashion products because they believe items are well-made, beautiful and durable and they feel more confident wearing them. R11 said:

"when I buy a foundation for my face, it always gives me confidence when I buy it from Dior or Channel rather than a high street brand such as Revlon or L'Oreal, maybe they are the same but I feel better when I buy a Chanel foundation, I have the same feeling toward my scarves".

R20 a lady in age 37 said:

"I found it very insulting when people think I buy luxury stuff to attract men, I have been working since I was 18 and now I can afford beautiful luxury stuffs, I buy them because I like them and because I can afford them, why is this so complicated to understand? I always wanted a Prada handbag, finally, I bought it because I could."

Some of the respondents admitted that when they wear luxury clothes they feel sexier and more confident and they agreed that they might look better for their partners but they didn't feel their personal relationship needed guarding by displaying their luxury items to other females.

R3 said:

"It is probably fair to say if I need to go to my husband's office I make sure I carry an expensive handbag and wear luxurious outfits [...] I want to make my husband proud and to do a bit of show off of his success". 
Only two respondents, one in her late twenties and one in early twenties mentioned demonstrating luxurious items indicates a better relationship with their partners and as a result they felt other female don't dare to target their partners and to flirt with them.

E, the personal shop assistant in fashion department in Harrods who has been working in Harrods Fashion Department for fourteen years and in her current position, who had a great insight about why females buy luxury fashion products added:

"There are many reasons why females spend a lot of money on luxury clothes, most of the time because they feel better about themselves, their bodies, their images and their looks but mostly they buy luxury items in a habitual way, they never have shopped differently, most of our customers are females who come from rich families, they were born in rich families, married to another rich person and buying luxury items for them is exactly like buying non-luxury items from a high street department store by someone with a modest income level. They buy luxury items because that's the only way that they know to shop".

She continued:

"We have two types of customers; the common type in Harrods is like the one I mention earlier; very wealthy customers and the second types are customers who buy luxury as a reward to themselves or when they can afford it, most of the time they think about quality and value for money and they select the product very carefully, when they book an appointment with me or my colleagues, they always mention they want to look better or slimmer or posher and they only mention their partners when they think the partner might not like what they are buying and use statements such as ' my husband doesn't like snakeskin leather handbag or leather pants' but customers hardly mentions things that their partners like".

E thought now, more number of females buy luxury products just because of the quality and functionality of the products rather than buying them for attracting men or compete with other women. She said even Asian and Middle Eastern clients don't bring the husbands or partner for shopping as often as they use to in the past and they make the decision quicker and independently. She mentioned that luxury fashion producers added more items of clothing for the use at home such as cashmere pyjamas and in-house-wears in comparisons with the past. She thought that's because females seek for more comfort in fashion and luxury products and they enjoy buying them for their quality and comfort rather than enhancing their look and male attraction.

Most of the respondent felt uncomfortable with the idea that the reason for their luxury shopping is mate retention strategies and they found that irrelevant. Five respondents were single and three of them mentioned they purchase the luxury products only for their own satisfaction and not even for the mate attraction.

\section{Findings:}

According to Mpinganjira, M (2014) research shows that customers have a range of underlying motivations triggering their shopping behaviour, but there are essentially two types of shopping motives: 1-Utilitarian: The conscious pursuit of an intended consequence. Essentially, meaning you're shopping "to get something done". 2-Hedonic: Related to intrinsic and emotional responses. In other words, you're shopping because you love it. It has stablished that most men tend to follow the utilitarian approach whereas most women tend to follow hedonic approach. If this approach is applicable to luxury buying behaviour, it shows a strong link between the female buyers to the luxury products or the actual shopping. These links have been refelected in the interviews when female shoppers mentioned they like to buy luxury products because of the quality, features and durability. Some respondents called the process of shopping pleasurable and socially entertaining.

The previous research didn't identify the 'empowered female luxury shoppers' intention as an important motivation for female luxury purchases. The idea of "I buy because I can" couldn't be linked to Intrasexual Theory and Signalling Theory. The result of previous research wasn't break down to dependency/independency of female or their age or cultural background. The changes in gender roles and therefore the impact of such changes on decision making process of luxury products hasn't been fully explored in many previous studies and so do on the money allocation and budgeting in the household and the impact of it on luxury shopping. Many of the respondents emphasized on the fact that they do not buy luxury products to attract long term potential partners nor to guard their partners.

\section{Bibliography:}


[1] Bahar Teimourpour, Kambiz Heidarzadeh Hanzaee, (2011) "The impact of culture on luxury consumption behaviour among Iranian consumers", Journal of Islamic Marketing, Vol. 2 Issue: 3, pp.309-328, https://doi.org/10.1108/17590831111164822

[2] Bain and Company (2015), "Global Luxury Goods Market Expected to Sustain Steady Momentum with 2-4 Percent Real Growth in 2015," May 21, http:// www.bain.com/about/press/press-releases/spring-2015worldwide-luxurygoods-update-press-release.aspx.

[3] Bev, Jennie S. and Vicki Zolenski (2011), "Braking into and Succeeding as Handbag Designer, Start Handbag Business," http://stylecareer.com/handbag-designer/.

[4] Buss, D. M. (1999). Evolutionary psychology: The new science of the mind. Boston: Allyn and Bacon.

[5] Buss, D. M. (2003). The evolution of desire: Strategies of human mating (rev. ed.) New York: Basic Books.

[6] Chao, A., and Schor, J. B. (1998). Empirical tests of status consumption: Evidence from women's cosmetics. Journal of Economic Psychology, 19, 107-131.

[7] D’Arpizio, Claudia (2012), "Luxury Goods Worldwide Market Study, Spring 2012 Update," Bain \& Company, accessed May 15, 2012, http://www.bain.com/about/press/press

[8] Griskevicius, V., Tybur, J. M., Sundie, J. M., Cialdini, R. B., Miller, G. F., and Kenrick, D. T. (2007). Blatant benevolence and conspicuous consumption: When romantic motives elicit strategic costly signals. Journal of Personality and Social Psychology, 93, 85-102.

[9] Hudders, L., Pandelaere, M. and Vyncke, P. (2013). Consumer meaning making: The meaning of luxury brands in a democratized luxury world. International Journal of Market Research, 55, 69-90.

[10] Khabiri, N., Mazloumi, S., Razeghi, P., \& Darvishvand, J. M. (2012). Influential Factors in Luxury Apparel Purchase Intentions among Iranian Customers, 2(12), 12670-12680.

[11] Laverie DA, Kleine III RE, Schultz Kleine S. Reexamination and extension of Kleine, Kleine, and Kernan's social identity model of mundane consumption: the mediating role of the appraisal process. Journal of Consumer Research 2002;28: 659-69. [March].

[12] Liselot Hudders UGent, Charlotte De Backer, M. F. and P. V. Ug. (2014). The Rival Wears Prada : Luxury Consumption as a Female Competition Strategy, 12(3), 570-587.

[13] Mercy Mpinganjira, UNDERSTANDING ONLINE REPEAT PURCHASE INTENTIONS: A RELATIONSHIP MARKETING PERSPECTIVE , Management, Vol. 19, 2014, 2, pp. 117-135

[14] Miller G. F. (1999). Waste is good. Prospect, Feb., 18-23.

[15] Miller G. (2000). Mental traits as fitness indicators: Expanding evolutionary psychology's adaptationism. Annals of the New York Academy of Sciences, 907, 62-74. Google Scholar Medline

[16] Miller G. F. (2009). Spent: Sex, evolution, and consumer behavior. New York: The Penguin Group.

[17] Nelissen R. M. A., and Meijers M. H. C. (2011). Social benefits of luxury brands as costly signals of wealth and status. Evolution and Human Behavior, 32, 343-355.

[18] Nunes, J.C., et al., Conspicuous consumption in a recession: Toning it down or turning it up? Journal of Consumer Psychology (2010), doi:10.1016/j.jcps.2010.11.002

[19] Prakash V. Sex roles and advertising preferences. Journal of Advertising Research 1992;32(3):43-52.

[20] Rosvall K. A. (2011). Intrasexual competition in females: Evidence for sexual selection. Behavioral Ecology, 22, $1131-1140$

[21] Saad G. (2007). The evolutionary bases of consumption. London: Lawrence Erlbaum Associates.

[22] Saad G. (2011). The consuming instinct: What juicy burgers, Ferraris, pornography, and gift giving reveal about human nature. New York: Prometheus Books.

[23] Saad G., and Vongas J. G. (2009). The effect of conspicuous consumption on men's testosterone levels. Organizational Behavior and Human Decision Processes, 110, 80-92.

[24] Samarahan, K. (2013). AN ANALYSIS OF LUXURY PRODUCT PURCHASING BEHAVIOR, 2(4), 219-227.

[25] Stokburger-Sauer, N. E., and Teichmann, K. (2011). Is luxury just a female thing? The role of gender in luxury brand consumption. Journal of Business Research, 66, 889-896.

[26] Sundie J. M., Kenrick D. T., Griskevicius V., Tybur J. M., Vohs K. D., and Beal D. J. (2011). Peacocks, porsches, and Thorstein Veblen: Conspicuous consumption as a sexual signaling system. Journal of Personality and Social Psychology, 100, 664-680.

[27] Tynan, Caroline, McKechnie, Sally and Chhuon, Celine, (2010), Co-creating value for luxury brands, Journal of Business Research, 63, issue 11, p. 1156-1163. 
[28] Wang, Y., and Griskevicius, V. (2014). Conspicuous consumption, relationships, and rivals: Women's luxury products as signals to other women. Journal of Consumer Research, 40, 834-854.

[29] Zahavi, A. (1975). Mate selection: A selection for a handicap. Journal of Theoretical

[30] Biology, 53, 205-214.

[31] References:

[32] https://www.statista.com/

[33] https://www.luxurydaily.com/men-spend-more-on-luxury-but-shop-the-same-amount-as-women-report/

[34] https://www.google.co.uk/search?q=harrods\&oq=harrods\&aqs=chrome..69i57j35i39|2j0|3.2955j0j4\&sourceid= chrome\&ie=UTF-8

[35] http://www.npr.org/sections/thetwo-way/2016/02/22/467674917/from-milan-to-tehran-luxury-fashion-houserobert-cavalli-struts-into-iran-market 